\title{
De meerwaarde van botscintigrafie bij honden met ongedefinieerd manken achteraan of niet-gelokaliseerde pijn op de achterhand
}

\author{
The value of bone scintigraphy in dogs with undefined hind limb lameness \\ or unlocalized pain
}

N. De Wilde, K. Peremans

Vakgroep Medische Beeldvorming van de Huisdieren en Orthopedie van de Kleine Huisdieren, Faculteit Diergeneeskunde, Universiteit Gent, Salisburylaan 133, Merelbeke

Kathelijne.Peremans@UGent.be

\section{AMENVATTING}

Botscintigrafie is een zeer gevoelige techniek om vroege veranderingen in de metabole activiteit van botstructuren weer te geven, zoals verhoogde bloedperfusie en/of verhoogde botremodellering. Botscintigrafie is uiterst geschikt als gevoelige diagnostische tool in het mankheidsonderzoek van de hond maar moet wegens de beperkte specificiteit gecombineerd worden met structurele beeldvormingstechnieken. In deze retrospectieve studie werden 194 patiënten opgenomen die mankten op de achterpoten en/of pijn vertoonden op de achterhand in de periode van 2001 tot en met 2020. Vierenzestig honden werden in de studie ingesloten op basis van patiëntengegevens. Bij de geselecteerde honden werden de bevindingen van de botscintigrafie vergeleken met de vaststellingen op andere beeldvormingsmodaliteiten die eventueel vooraf uitgevoerd werden en met de beeldvorming die achteraf gebeurde op basis van de scintigrafiebeelden. Uit deze retrospectieve studie kan besloten worden dat botscintigrafie zijn nut bewijst bij aandoeningen, waarbij het voorgaande onderzoek niet conclusief was.

\begin{abstract}
Bone scintigraphy is a very sensitive technique to detect early changes in the metabolic activity of bone structures such as a higher blood perfusion and/or bone remodeling. Therefore, bone scintigraphy is highly suited as sensitive diagnostic tool in the lameness examination of dogs. Due to the limited specificity of this technique, scintigraphy has to be combined with structural imaging techniques. In this retrospective study, 194 patients with complaints of limping and/or pain in the hind legs were observed in the period of 2001 until 2020. Sixty-four dogs were included in the study based on patient data and results. In the selected dogs, the findings on the scintigraphy scans were compared to the results of prior examinations and to the imaging techniques which were taken based on the scintigraphy images. Based on this retrospective study, it can be concluded that bone scintigraphy is useful in conditions where previous examinations were inconclusive.
\end{abstract}

\section{INLEIDING}

Achterhandsmanken bij de hond wordt doorgaans onderzocht tijdens het klinisch en orthopedisch onderzoek, inclusief palpatie, bepaling van de pijnlijkheid en "range of motion" (ROM) van de gewrichten, het bekijken van de gang en, indien geïndiceerd, een neurologisch basisonderzoek.

Wanneer het manken zich in de achterhand situeert, is er tijdens het klinisch onderzoek vaak een lage houding van de kop waarneembaar bij beweging en wordt er een hogere belasting geplaatst op de voorpoten. Bij heupaandoeningen kan een 'waggelende gang' voorkomen. Wanneer er knieproblemen aanwezig zijn, wordt de aangetaste poot vaak verder naar voren geplaatst, waardoor een gestrekte pas ontstaat. Het op en neer bewegen van de staart bij het stappen kan eveneens wijzen op een probleem aan de achterhand (Leach et al., 1977). Naast het bewegingsonderzoek volgt er palpatie en manipulatie van de verschil- 
lende skeletregio's om de lokalisatie van pijn te bepalen. De oorzaak van pijn kan klinisch moeilijker vast te stellen zijn wanneer er met behulp van manipulatie geen lokalisatie kan bepaald worden en/of wanneer er sprake is van een multifocale oorsprong (Schwarz et al., 2004), wat gerichte beeldvorming bemoeilijkt. Het karakter van de hond kan eveneens een rol spelen in het al dan niet lokaliseren van het probleem. Als vervolg op het klinisch onderzoek worden medische beeldvormingstechnieken ingeschakeld.

De meest gebruikte en toegankelijke beeldvormingsmodaliteit in de eerstelijnspraktijk is radiografie. Radiografie is ideaal voor het beoordelen van beenderige structuren. Radiografische veranderingen treden echter meestal later op, waardoor aanwezige aandoeningen niet altijd (vroeg) gediagnosticeerd kunnen worden. Langdurige problemen zijn vaker zichtbaar op radiografieën vanwege de secundaire veranderingen die optreden, zoals osteoartrose. Het bijkomende nadeel is dat een driedimensionale structuur omgezet wordt in een tweedimensionaal radiografisch beeld en er daardoor superpositie van verschillende structuren optreedt.

Complexe gewrichten en subtiele botlaesies zijn dan ook beter zichtbaar op een driedimensionale weergave zoals bij computertomografie (CT). Osteolyse en sclerose zijn eerder zichtbaar op een CT-scan dan op radiografieën aangezien een CT-scan verschillen in densiteit van zelfs $0,5 \%$ in beeld brengt (Hoskinson en Tucker, 2001); dit in tegenstelling tot radiografisch onderzoek, waarbij er 30-50\% verschil in densiteit nodig is. Bij CT is er evenmin sprake van superimpositie van bovenliggende structuren aangezien de roterende detectoren de uitgezonden straling van een eveneens roterende röntgenbuis opvangen en er zo doorsnedes worden gemaakt van het lichaamsdeel (Tidwell en Jones, 1999; Ohlerth en Scharf, 2007).

Bij een vermoeden van aandoeningen van het centrale zenuwstelstel (Pooya et al., 2004) of bij musculoskeletale problemen wordt vaak een "magnetic resonance imaging scan (MRI) uitgevoerd. Daarbij wordt een magnetisch veld gecreëerd en worden radiogolven doorheen het lichaam gezonden. De gewijzigde magnetische signalen vormen via ontvangstspoelen een driedimensionaal beeld.

Niet zelden wordt er beroep gedaan op botscintigrafie wanneer er met behulp van de hierboven genoemde structurele beeldvormende modaliteiten, i. e. radiografie, CT, MRI, geen lokalisatie toegeschreven kan worden aan het klinische achterhandsprobleem.

Op de Faculteit Diergeneeskunde (UGent) is botscintigrafie minder duur dan CT en MRI; het is bovendien een zeer gevoelige techniek en leent zich uitstekend om in een vroeg stadium veranderingen in de metabole activiteit van botstructuren weer te geven, zoals verhoogde bloedperfusie en/of veranderde botremodellering. Dit uit zich bij verhoogde botactiviteit in de vorm van "hotspots" en bij botdestructie in "coldspots". Opname kan gebeuren op het niveau van de afzonderlijke ledematen maar ook een opname van het hele lichaam in één scanbeurt ("total body scan") is mogelijk.

Methyleendifosfonaat-gelabeld technetiumO ${ }_{4}^{99 \mathrm{~m}}$, afgekort als ${ }^{99 \mathrm{~m}} \mathrm{Tc}-\mathrm{MDP}$ wordt het vaakst gebruikt voor botscintigrafie. Deze radioactieve stof wordt intraveneus geïnjecteerd en bindt aan de blootgestelde hydroxyapatietcomponent van bot op plaatsen waar een actieve botremodellering gebeurt (Balogh et al., 1999). Door middel van een gammacamera wordt een scan genomen twee à drie uur na injectie van ${ }^{99 \mathrm{~m}} \mathrm{Tc}$ MDP. Hierbij capteert de gammacamera straling die vanuit de patiënt komt. Deze straling wordt dan omgezet in een elektrisch signaal dat uiteindelijk resulteert in een beeld. Er is de tweedimensionale beeldvorming (planaire scans) die te vergelijken is met de tweedimensionale beeldvorming bij radiografie. Daarnaast bestaat de mogelijkheid om met de hedendaagse gammacamera's die bij kleine huisdieren gebruikt worden, ook driedimensionale beelden te maken tijdens hetzelfde onderzoek. Dit onderzoek wordt "single photon emission computed tomography" (SPECT) genoemd en is sinds kort ook mogelijk bij paarden (Harding et al., 2021).

Regio's waar een verhoogde botremodellering aanwezig is, zijn reeds na enkele uren zichtbaar op de botscan; dit in tegenstelling tot radiografische veranderingen die pas laattijdig gezien kunnen worden (Balogh et al., 1999; Jankowski et al., 2003; Schwarz et al., 2004; Samoy et al., 2008). Een van de nadelen van botscintigrafie is de beperkte spatiale resolutie (scherpheid/detail van beelden). Dit wordt opgevangen door "high resolution single photon emission computed tomography" (HiSPECT ), een gammacamera die over aangepaste collimatoren beschikt, waardoor anatomische lokalisatie bijvoorbeeld binnen een gewricht, verbeterd wordt (Peremans et al., 2013). Verder is botscintigrafie zeer gevoelig (snelle diagnose van botremodellering) maar niet specifiek (elke botremodellering ongeacht de onderliggende pathologie resulteert in een gelijkaardig beeld), waardoor de klinische situatie (infectie versus tumor of trauma) belangrijk is voor de diagnose. Dit leidt eveneens tot de inzet van anatomische beeldvorming/artroscopie die de diagnostiek verder kan verfijnen (Debruyn et al., 2013, Hoskinson en Tucker, 2001).

Het doel van deze retrospectieve studie was het analyseren van de bevindingen tijdens botscintigrafisch onderzoek van honden met achterhandsproblemen en niet-gelokaliseerde pijnklachten, waarbij er met behulp van andere diagnostische middelen en beeldvormingsmodaliteiten geen duidelijke oorzaak van het probleem gevonden kon worden. Significante veranderingen vastgesteld op een botscan werden vervolgens vergeleken met de vaststellingen via andere modaliteiten, zoals radiografieën, CT en MRI, die vooraf uitgevoerd werden en met die van een specifieker gebied die op basis van de botscintigrafie werden genomen. 


\section{MATERIAAL EN METHODEN}

De retrospectieve studie liep van 2001 tot en met december 2020. Alle gegevens werden uit het papieren archief en de digitale databanken van de Faculteit Diergeneeskunde (UGent) verzameld.

In die periode werden er op de Faculteit Diergeneeskunde in totaal 371 botscans bij honden uitgevoerd. Hiervan werden er 194 botscans uitgevoerd bij honden met niet-gelokaliseerde pijn of met specifieke achterhandsproblemen.

De patiënten die in het onderzoek werden opgenomen, werden geselecteerd op basis van de anamnese (klachten, pijn op de achterhand, manken) en op basis van de uitgevoerde scintigrafieën (scans van de achterpoten, de sacrale regio, het pelvisgebied, de rug en scans van het volledige lichaam met bevindingen op de achterhand). Het kliniekprogramma van Kleine Huisdieren met alle patiëntendossiers werd gebruikt om het signalement, de anamnese en (resultaten van) uitgevoerde onderzoeken aan te vullen.

Gevallen waarbij verslagen onvolledig waren, er geen afwijkingen op scintigrafie vastgesteld werden en/of waarbij er geen bijkomende onderzoeken naast scintigrafie gebeurden om tot een definitieve diagnose te komen, werden niet in de studie ingesloten.

Vervolgens werden de resultaten in een tabel verwerkt om alle patiëntengegevens duidelijk weer te geven en een vergelijking te maken tussen de bevindingen van eerder onderzoek, de botscans en daaropvolgende beeldvormende onderzoeken. De verschillende diagnosen werden opgesomd, gerangschikt volgens anatomische lokalisatie en er werd nagegaan in hoeveel gevallen verder onderzoek van de aangetaste locaties op botscan resulteerden in een diagnose.

\section{RESULTATEN}

In totaal werden er 194 patiëntendossiers in beschouwing genomen. Bij twintig gevallen ontbraken gegevens over signalement, anamnese of scintigrafieresultaten. Bij 18 honden werden er geen afwijkingen gevonden op scintigrafie en bij 86 honden werd er geen verder onderzoek uitgevoerd ondanks de verhoogde opname die tijdens de botscan werd vastgesteld. Bij zes honden kon er na verder onderzoek geen definitieve diagnose gesteld worden. Bij de definitieve groep van 64 honden werd gericht onderzoek uitgevoerd met behulp van medische beeldvorming $(n=62)$ en artroscopie $(n=2)$. Van deze 64 honden waren er 35 mannelijk, waarvan vijf gecastreerd. Negenentwintig honden waren vrouwelijk, waarvan 12 gesteriliseerd. De gemiddelde leeftijd van de geselecteerde patiënten was vijf jaar (variërend van negen maanden tot elf jaar).

Tabel 1. Vergelijking van de bevindingen tijdens voorafgaand onderzoek en tijdens de scintigrafiescan.

\begin{tabular}{|c|c|c|c|c|c|c|c|c|c|}
\hline \multirow[t]{2}{*}{ Onderzoek } & \multirow[t]{2}{*}{ Aantal } & \multirow[t]{2}{*}{$\begin{array}{c}\text { Geen } \\
\text { afwijkingen } \\
\text { op initieel } \\
\text { onderzoek }\end{array}$} & \multirow[t]{2}{*}{$\begin{array}{c}\text { Wel } \\
\text { afwijkingen } \\
\text { zelfde regio } \\
\text { op scintigrafie }\end{array}$} & \multirow[t]{2}{*}{$\begin{array}{c}\text { Afwijkingen } \\
\text { op initieel } \\
\text { onderzoek }\end{array}$} & \multirow[t]{2}{*}{$\begin{array}{l}\text { Afwijking } \\
\text { zelfde } \\
\text { regio op } \\
\text { scintigrafie }\end{array}$} & \multicolumn{4}{|c|}{$\begin{array}{c}\text { Afwijkingen andere regio } \\
\text { op scintigrafie dan } \\
\text { aangetaste regio } \\
\text { initieel onderzoek }\end{array}$} \\
\hline & & & & & & 鵕 & 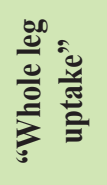 & $\stackrel{\mathscr{E}}{\mathscr{E}}$ & 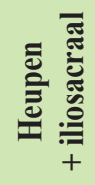 \\
\hline Geen & 31 & & & & & & & & \\
\hline \multicolumn{10}{|l|}{ Radiografie } \\
\hline Heupen & 22 & 14 & 0 & 8 & 5 & 1 & 1 & 1 & 0 \\
\hline Wervelkolom & 11 & 6 & 3 & 5 & 3 & 1 & 0 & 0 & 1 \\
\hline Knieën & 10 & 7 & 2 & 3 & 3 & 0 & 0 & 0 & 0 \\
\hline Tarsi & 3 & 3 & 0 & 0 & 0 & 0 & 0 & 0 & 0 \\
\hline $\mathrm{LiVP}+\mathrm{ReAP}$ & 1 & 0 & 0 & 1 & 1 & 0 & 0 & 0 & 0 \\
\hline \multicolumn{10}{|l|}{ CT } \\
\hline Wervelkolom & 6 & 2 & 0 & 4 & 1 & 1 & 0 & 1 & 1 \\
\hline Knieën & 1 & 1 & 0 & 0 & 0 & 0 & 0 & 0 & 0 \\
\hline \multicolumn{10}{|l|}{ MRI } \\
\hline Wervelkolom & 4 & 2 & 1 & 2 & 1 & 0 & 0 & 0 & 1 \\
\hline \multicolumn{10}{|l|}{ Artrocentese } \\
\hline Heup & 1 & 1 & 0 & 0 & 0 & 0 & 0 & 0 & 0 \\
\hline
\end{tabular}


Tabel 2. Vergelijking van de bevindingen tijdens verder onderzoek en bevindingen tijdens een eerdere scintigrafiescan.

\begin{tabular}{lccc}
\hline Verder onderzoek & Aantal & $\begin{array}{c}\text { Afwijking in dezelfde } \\
\text { regio aangetoond met scintigrafie }\end{array}$ & $\begin{array}{c}\text { Afwijking in regio niet } \\
\text { aangetoond met scintigrafie }\end{array}$ \\
\hline Radiografie & 33 & 33 & 0 \\
Radiografie + CT & 6 & 4 & 2 \\
Radiografie + CT + arthroscopie & 1 & 1 & 0 \\
Radiografie + CT + MRI + echo & 1 & 1 & 0 \\
Radiografie+ CT + MRI + biopt & 1 & 1 & 0 \\
Radiografie + MRI & 1 & 1 & 0 \\
CT & 11 & 9 & 2 \\
CT + MRI & 2 & 1 & 1 \\
CT + MRI + botbiopt & 1 & 1 & 0 \\
CT + echo & 1 & 1 & 0 \\
CT + echo + biopt & 1 & 1 & 0 \\
CT + autopsie & 1 & 1 & 0 \\
CT + US + FNA & 1 & 0 & 0 \\
MRI & 2 & 1 & 2 \\
Artroscopie & 1 & & 0 \\
\hline
\end{tabular}

De rassen vertegenwoordigd in deze retrospectieve studie waren de Duitse herder $(n=8)$, labrador retriever $(n=8)$, Mechelse herder $(n=8)$, border collie $(n=5)$, golden retriever $(n=4)$, rottweiler $(n=4)$, boxer $(n=3)$, berner sennen $(n=2)$, bouvier des Flandres $(n=2)$, Duitse staander $(n=2)$, jack russelterriër $(n=2)$. Van de volgende rassen werd telkens één hond ingesloten: Afghaanse windhond, Bordeaux dog, bulterriër, chihuahua, deerhound, dobermann, Drentse patrijshond, Duitse dog, Engelse buldog, Engelse cockerspaniël, flatcoated retriever, hovawart, Italiaanse brak, kruising, maltezer en Schotse terriër.

Vooraleer het scintigrafisch onderzoek werd uitgevoerd, werden bij dertig dieren radiografieën genomen van een of meer regio's, zes dieren ondergingen een CT-scan en drie honden een MRI-scan. Bij één hond werd ook artrocentese van de heup uitgevoerd. Bij zes honden werd meer dan één beeldvormingsmodaliteit uitgevoerd en bij 31 patiënten werd er voorafgaand aan de scintigrafiescan geen beeldvormingsonderzoek gerapporteerd. In vijftien gevallen leidde het voorafgaand onderzoek tot een definitieve diagnose. In Tabel 1 wordt een overzicht gegeven van de bevindingen tijdens de voorafgaande onderzoeken en deze tijdens het scintigrafisch onderzoek. Veertien regio's bij tien honden werden zowel aangetoond tijdens een voorafgaand onderzoek als tijdens het scintigrafisch onderzoek. Zes regio's vertoonden geen afwijkingen bij voorafgaand onderzoek terwijl ze een verhoogde activiteit vertoonden tijdens de scintigrafiescan.

Bij zestig van de 64 geselecteerde honden werd er structurele beeldvorming (RX, CT, MRI) uitgevoerd op basis van de hotspot(s) aangetoond tijdens het botscintigrafisch onderzoek. Bij twee honden werd een echografisch onderzoek uitgevoerd en twee honden ondergingen artroscopie. Bij de meerderheid van de honden $(n=52)$ werden er op meer dan één lo- kalisatie hotspots vastgesteld. Bij 27 honden werden niet alle hotspots verder onderzocht. Bij tien honden met multipele hotspots waren er regio's met een verhoogde activiteit die geen afwijkingen vertoonden op verdere beeldvorming. In Tabel 2 wordt weergegeven in hoeveel gevallen er dankzij gerichte beeldvorming op basis van de scintigrafieresultaten een diagnose gesteld kon worden. Slechts in zeven gevallen werd de aangetaste regio tijdens verder beeldvormingsonderzoek niet vooraf vastgesteld met scintigrafie. In 57 gevallen kwamen de bevindingen tijdens verder onderzoek (structurele beeldvorming/ artroscopie/ artrocentese/ echografie) overeen met de bevindingen tijdens het scintigrafisch onderzoek. Bij 33 honden van de 57 werd elke aangetaste regio verder onderzocht. Bij zes honden werd op het onderzoek voorafgaand aan de scintigrafiescan vastgesteld dat dezelfde regio was aangetast als op het structurele beeldvormingsonderzoek dat volgde op de scintigrafiescan.

Volgend op de scintigrafiescan werden radiografieën genomen $(n=43)$ en CT-scans $(n=27)$ en MRIscans $(n=8)$ uitgevoerd. In drie gevallen werd een biopt genomen van de verdachte regio. Bij twee honden werd echografisch onderzoek uitgevoerd en twee dieren ondergingen artroscopie. Bij één dier werd een fijnenaaldaspiraat (FNA) genomen van de verdachte regio. $\mathrm{Na}$ de bevindingen op de scintigrafiescan werd bij 16 honden meer dan één beeldvormingstechniek uitgevoerd. Bij zeven honden werden er geen structurele veranderingen opgemerkt met CT $(n=2)$, MRI $(n=2)$, of met de combinatie van RX en CT $(n=2)$ en CT en MRI $(n=1)$ van de regio die tijdens het scintigrafisch onderzoek werd aangetoond.

De aandoeningen die werden vastgesteld met structurele beeldvorming op basis van de hotspots waren gelokaliseerd ter hoogte van de rug $(n=27)$, het heupgewricht $(n=13)$, de tarsusregio $(n=13)$, het kniege- 
wricht $(\mathrm{n}=7)$, het iliosacrale gewricht $(\mathrm{n}=7)$, de tibia $(n=3)$, metatarsi $(n=2)$, tenen $(n=1)$, spieren $(n=1)$, zenuwen (nervus ischiadicus) $(\mathrm{n}=1)$.

De aandoeningen van de rug betroffen de tussenwervelschijf, i. e. discus hernia $(\mathrm{n}=2)$, "bulging" van de lumbosacrale tussenwervelschijf $(n=2)$ en dehydratatie van de lumbosacrale tussenwervelschijf $(n=2)$. In enkele gevallen $(n=2)$ werd er collaps van de lumbosacrale intervertebrale ruimte beschreven. Spondylosis deformans kwam in 13 gevallen voor en dan vooral ter hoogte van de lumbosacrale streek $(n=5)$ en de thoracale wervels $(n=4)$. Discospondylitis kwam vooral lumbosacraal $(n=4)$ voor bij een beperkt aantal honden $(n=5)$. Degeneratieve gewrichtsafwijkingen $(n=23)$ werden bij een groot aantal patiënten gediagnosticeerd. De volgende degeneratieve afwijkingen werden het vaakst vastgesteld: lumbosacraal $(n=4)$, iliosacraal $(n=4)$ en ter hoogte van de heupen $(n=4)$. Ter hoogte van het iliosacrale gewricht werd een fragment aangetoond $(n=1)$ en werd bij meerdere honden $(n=3)$ ontsteking (sacro-iliitis) vastgesteld.

Naast de degeneratieve veranderingen werden bij een groot aantal honden aandoeningen ter hoogte van de heupen vastgesteld. Hierbij kwamen heupdysplasie $(n=4)$ en heupsubluxatie $(n=2)$ voor maar ook effusie van het gewricht $(n=1)$ en infectie van een heupprothese $(\mathrm{n}=1)$.

De tarsus was een vaak aangetaste regio in deze retrospectieve studie. Ter hoogte van het laterale collaterale ligament van de tarsus werd bij een patiënt een enthesiofyt vastgesteld $(n=1)$ en sclerose ter hoogte van de aanhechting van ditzelfde ligament werd bij een andere patiënt $(\mathrm{n}=1)$ aangetoond. Een afwijkende zachte botstructuur $(n=1)$, een oude avulsiefractuur van het mediale collaterale ligament of oud trauma van de mediale malleolus $(\mathrm{n}=1)$, opzetting $(\mathrm{n}=1)$, enthesopathie $(n=1)$ en subluxatie $(n=1)$ werden eveneens ter hoogte van de tarsus gediagnosticeerd. Daarnaast werden er fragmenten aangetoond in de tarsale regio $(n=5)$ en ter hoogte van de metatarsi $(n=1)$. Er werd ook een oude fractuur van een laterale teen gezien $(\mathrm{n}=1)$.

De knieën vertoonden effusie $(n=4)$ en rupturen van de voorste kruisband $(\mathrm{n}=2)$.

Aandoeningen van de spieren werden bij enkele honden $(n=4)$ aangetoond. Deze betroffen myositis/ myotendinitis, veralgemeende letsels van de spieren van de achterhand en twee laesies van de spieren/ ligamenten ter hoogte van de heup. Neoplastische processen werden gediagnosticeerd bij vier patiënten en sterk vermoed bij twee patiënten.

Bij een klein aantal honden $(n=5)$ was er sprake van "whole leg uptake", waarbij er een veralgemeende verhoogde opname van de radioactieve stof ${ }^{99 \mathrm{~m}} \mathrm{Tc}-\mathrm{MDP}$ gezien kon worden in eenzelfde lidmaat. Deze bevinding kan in verband gebracht worden met neurologische aandoeningen wanneer een lidmaat een uitgesproken verhoogde opname vertoont zonder focale hotspots (Peremans et al., 2007). In deze studie was er in één geval verdikking van de nervus ischia- dicus die middels $\mathrm{CT}$ bevestigd werd. Na CT, echografisch onderzoek en fijnenaaldaspiratie werd bij één hond een rhabdomyosarcoom in het bekken vastgesteld. Bij één andere patiënt werden er met behulp van RX, CT, MRI en tenslotte in spierbiopten multifocale letsels aangetoond ter hoogte van de spieren van één achterpoot. Tijdens het artroscopisch onderzoek werd er bij één hond ter hoogte van de tarsus een zone met zacht bot gezien, met onregelmatige synovi in het laterale gewrichtscompartiment. Bij één hond kon er met CT enkel bilaterale effusie van de knieën gediagnosticeerd worden naast milde spondylosis deformans en hypoplasie van de caudale thoracale en lumbale facetgewrichten.

Een groot aantal honden $(\mathrm{n}=22)$ werd gediagnosticeerd met aandoeningen ter hoogte van verschillende regio's. Bij vier honden, waarvan er twee geen klachten op de voorpoten vertoonden, werden eveneens aandoeningen van de voorhand vastgesteld. Ter hoogte van de voorpoten was de locatie van de gediagnosticeerde afwijkingen als volgt: elleboog $(n=3)$, schouder $(n=2)$ en humerus $(n=1)$.

\section{DISCUSSIE}

Bij 57 honden stemde verder onderzoek (structurele beeldvorming/ artroscopie/ artrocentese/ echografie) overeen met de bevindingen op de scintigrafiescan. Bij 33 van deze 57 honden werd er voor elke aangetaste regio verder onderzoek uitgevoerd. In 27 gevallen werden multipele hotspots aangetoond waarbij niet van alle regio's een structureel beeldvormingsonderzoek werd uitgevoerd. In vier gevallen werden er geen afwijkingen gevonden tijdens de structurele beeldvorming van alle verdachte regio's die op de scintigrafiescan aangetoond werden.

Bij een groot aantal afwijkende botscans $(n=86)$ werd geen vervolgonderzoek gepland of het was in de betreffende dossiers niet aanwezig. Hierdoor ontbreekt er een groot deel aan informatie over de definitieve diagnosen.

Zoals eerder vermeld is scintigrafie een zeer sensitieve techniek maar is het laag-specifiek. Dit wil zeggen dat ondanks het feit dat er duidelijke regionale hotspots te zien zijn, er niet altijd een exacte diagnose gesteld kan worden. De klassieke planaire botscintigrafie heeft bovendien een gelimiteerde spatiale resolutie, waardoor de exacte anatomische lokalisatie, bijvoorbeeld binnen het gewricht, niet mogelijk is. Een belangrijk punt is dat er een groot verschil is in wat de verschillende beeldvormingstechnieken in beeld kunnen brengen. Met scintigrafie kunnen fysiologische veranderingen aangetoond worden zoals botremodellering in een vroeg stadium. Gezien fysiologische veranderingen in het algemeen vroeger voorkomen dan anatomische, kunnen vroege stadia van bepaalde aandoeningen zichtbaar worden terwijl er nog geen afwijkingen gezien worden met structurele beeldvorming. Bij tien honden met multipele 
hotspots werden er niet van alle hotspots afwijkingen vastgesteld met structurele beeldvorming. Gezien de hoge gevoeligheid van scintigrafie kan dit een gevolg zijn van fysiologisch verhoogde activiteit door de veranderde biomechanica in andere gewrichten/skeletstructuren als gevolg van de primaire aandoening. Niet elke botremodellering wijst immers de facto op een aandoening. Bij paarden is bekend dat afhankelijk van de sport waarin ze gebruikt worden, er bepaalde skeletregio's meer belast worden en er fysiologische botremodellering plaatsvindt (Dik et al., 2015). Hierbij kunnen meerdere hotspots voorkomen die meestal een matige opname vertonen en op zich niet onmiddellijk van klinisch belang zijn. In de voorliggende studie konden bij 57 van de 64 honden de voorafgaande onderzoeken desalniettemin bevestigd worden of kon er een volledige diagnose gesteld worden met de specifieke verdere onderzoeken gebaseerd op de scintigrafiebevindingen. Slechts bij zeven patiënten kon een aangetaste regio niet aangetoond worden middels scintigrafie. Hier kan de vraag gesteld worden of zich in die regio wel degelijk het mankheidsprobleem stelde gezien botscintigrafisch onderzoek had aangetoond dat de regio fysiologisch niet actief was.

Aangezien deze resultaten bekomen werden via een retrospectieve studie zijn er de typische beperkingen verbonden aan dit soort onderzoek. De voornaamste beperking van de voorliggende studie was dat gegevens dikwijls onvolledig waren en dat het onderzoek niet volgens een bepaald, vooraf vastgelegd protocol verliep. De selectie van de honden voor deze studie werd voornamelijk gelimiteerd door de onvolledigheid van patiëntendossiers.

\section{CONCLUSIE}

Uit deze beperkte retrospectieve studie kan besloten worden dat botscintigrafie zijn nut bewijst bij aandoeningen waarbij het voorafgaande onderzoek niet conclusief is. De grote meerderheid van hotspots wordt geassocieerd met degeneratieve veranderingen ("degenerative joint disease") in meerdere gewrichten. Afgaand op de overeenkomst van de scintigrafiebeelden met de bevindingen vastgesteld met andere beeldvormingsmodaliteiten, en het grote aantal honden waarbij meerdere hotspots aangetoond werden, kan vastgesteld worden dat verder onderzoek steeds nodig is om tot een definitieve diagnose te komen. Een prospectieve studie met actieve opvolging van honden met aangetaste regio's op de botscan maar geen afwijkingen tijdens structurele beeldvorming zou goed aansluiten bij deze retrospectieve studie, om de diagnostische waarde van scintigrafie binnen het mankheidsonderzoek nog beter in kaart te brengen.

\section{REFERENTIES}

Balogh L., Andócs G., Thuróczy J., Németh T., Láng J. Bodó K., Jánoki G.A. (1999). Veterinary Nuclear Medi- cine. Scintigraphical Methods - review. Acta Veterinaria Brno 68 (4), 231-239.

Debruyn K., Peremans K., Vandermeulen E., Van Ryssen B., Saunders J.H. (2013). Evaluation of semi-quantitative bone scintigraphy in canine elbows. The Veterinary Journal 196 (3), 424-430.

Dik K.J., Weller R., Saunders J.H., Van den Belt A.J.M., Bergman H.J., De Sadeleer C., Peremans K. (2015). Diagnostic Imaging of Equine Sport Injuries. In: Glaudemans A., Dierckx R., Gielen, J., Zwerver J. (editors). Nuclear Medicine and Radiology Imaging in Sports Injuries. Springer, Berlin, Heidelberg, pp 1007-1034.

Harding P.G., Tually P., Cullimore A.M., Peremans K. (2021). Case report: Single-photon emission computed tomography of the pelvis and lumbar spine contributes to the diagnosis of injury in two horses. Equine Veterinary Education. https://doi.org/10.1111/eve.13504

Hoskinson J.J., Tucker R.L. (2001). Diagnostic imaging of lameness in small animals. Veterinary Clinics of North America. Small Animal Practice 31, 165-180.

Jankowski M.K., Steyn P.F., Lana S.E., Dernell W.S., Blom C.M., Uhrig J.L., Lafferty M., Withrow S.J. (2003). Nuclear scanning with 99mTc-HDP for the initial evaluation of osseous metastasis in canine osteosarcoma. Veterinary and Comparative Oncology 1 (3), 152-158.

Leach D., Sumner-Smith G., Dagg A.I. (1977). Diagnosis of lameness in dogs: a preliminary study. Canine Veterinary Journal 18 (3), 58-63.

Ohlerth S., Scharf G. (2007). Computed tomography in small animals - Basic principles and state of the art applications. The Veterinary Journal 173 (2), 254-271.

Peremans K., Van Caelenberg A., Vandermeulen E., Vermeire S., van Bree H. (2007). "Whole leg" uptake on the bone scintigram of the lame dog. In: European Association Of Veterinary Diagnostic Imaging- Annual Meeting 2007.

Peremans K., Duchateau L., Vermeire S., Vandermeulen E., Dobbeleir A., Gielen I., Polis I., Van Rijssen B., De Bakker E., Saunders J., et al. (2013). The use of the HiSPECT bone scan in canine flexor enthesopathy and coronoid pathology. Research in Veterinary Science 94, 628-633.

Pooya H.A., Séguin, B., Tucker, R.L., Gavin P.R., Tobias K. (2004). Magnetic resonance imaging in small animal medicine: Clinical applications. Compendium on Continuing Education for the Practicing Veterinarian 26, 292 302.

Samoy Y., Van Ryssen B., Van Caelenberg A., Gielen I., Van Vynckt D., Van Bree H., De Bacquer D., Peremans K. (2008). Single-phase bone scintigraphy in dogs with obscure lameness. Journal of Small Animal Practice 49, 444-450.

Schwarz T., Johnson V.S., Voute L., Sullivan M. (2004). Bone scintigraphy in the investigation of occult lameness in the dog. Journal of Small Animal Practice 45, 232237.

Tidwell A.S., Jones J.C. (1999). Advanced imaging concepts: a pictorial glossary of CT and MRI technology. Clinical Techniques in Small Animal Practice 14 (2), 65111 . 